\title{
PCBs risk evaluation, environmental protection, and management: 50-year research and counting for elimination by 2028
}

\author{
Larry W. Robertson ${ }^{1}$ (D) $\cdot$ Roland Weber ${ }^{2} \cdot$ Takeshi Nakano $^{3} \cdot$ Niklas Johansson $^{4}$
}

Received: 7 May 2018 / Accepted: 31 May 2018 / Published online: 13 June 2018

(C) Springer-Verlag GmbH Germany, part of Springer Nature 2018

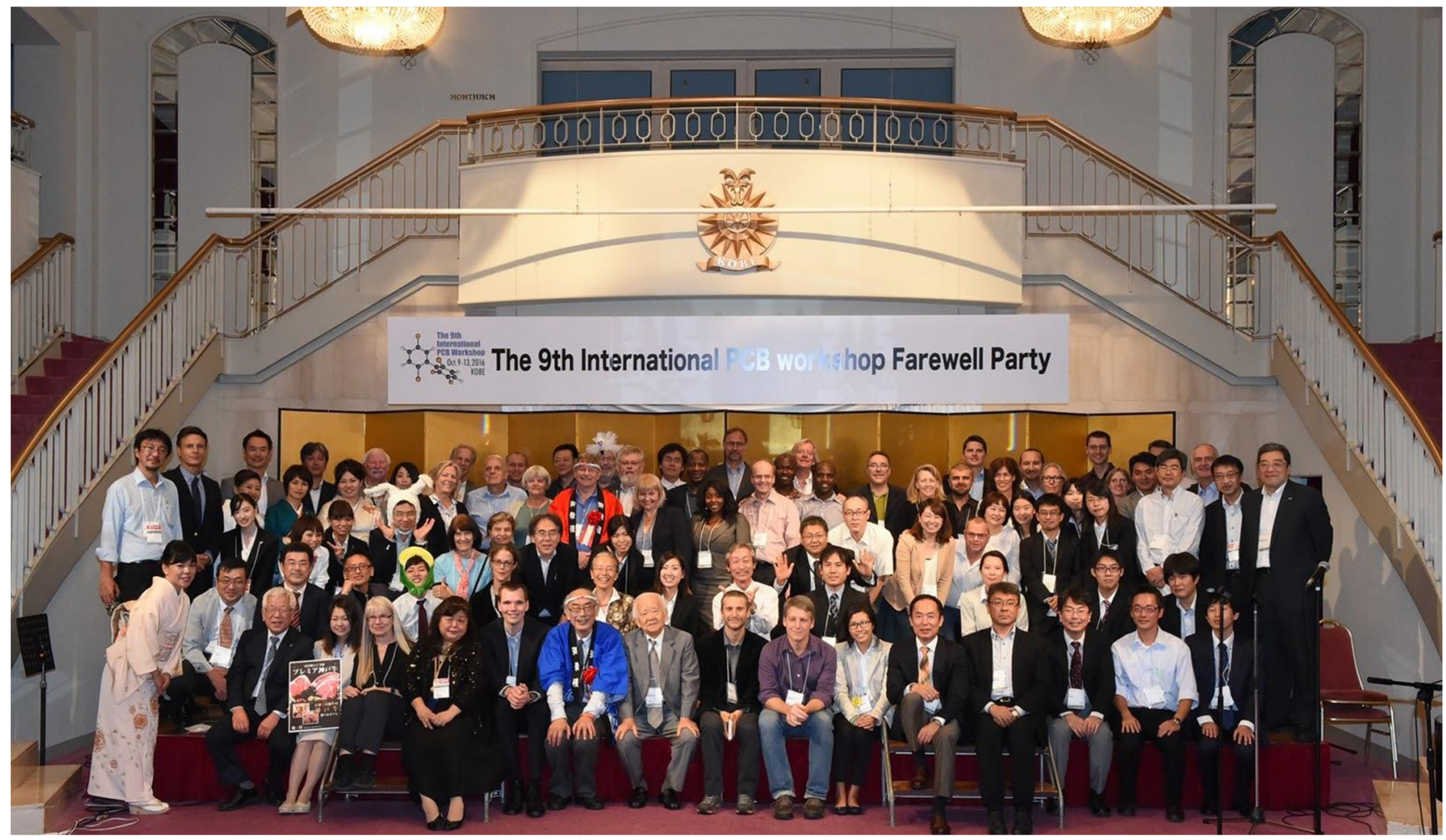

\section{Responsible editor: Philippe Garrigues}

$\triangle$ Larry W. Robertson

larry-robertson@uiowa.edu

1 University of Iowa, Iowa City, IA, USA

2 POPs Environmental Consulting, Schwäbisch Gmünd, Germany

3 Osaka University, Research Center for Environmental Preservation, Osaka, Japan

4 Swedish EPA and Karolinska Institute, Stockholm, Sweden http://ee-net.ne.jp/pcb2016e

The Ninth International PCB Workshop, entitled "PCBs Risk evaluation and environmental protection" took place at the Kobe International Convention Center, Kobe, Japan, during October 9-13, 2016. Sunday, October 9, 2016, the day of the opening of the Workshop, was highlighted by a feast, the greeting of old friends and colleagues, and the meeting new ones.

On Monday morning, October 10, 2016, an important engagement activity of the Workshop, a Citizen's Session 
(in Japanese) was presented for a lay audience. Yoshina Usui, of the Hyogo Prefectural Sumahigashi High School, and Keiichi Tanno, of the Kobe City College of Nursing, chaired this session. The well-attended presentations ranged over topics of general interest including environmental pollution, waste reduction and recycling, and the public perception of these issues.

Prof. Masatoshi Morita, Ehime University, presented a plenary lecture, entitled "PCBs in Japan: history and the road to elimination." He introduced the history of polychlorinated biphenyls (PCBs) in Japan over 50 years. PCBs were used widely for industrial purposes until 1973 because of their stable physicochemical properties and excellent electric characteristics of high insulation and polarity. However, PCBs have long-term toxicity, neurological and endocrine disruption, and persistency bioaccumulation nature for human health and environment including those characteristics demonstrated in the Yusho poisoning. This shift in understanding happened in the half century by the development of toxicology, analysis and data accumulation of environmental monitoring, and growing social concern. Stockholm convention decided that persistent organic pollutants (POPs) including PCBs should disappear globally but the road to this end is not easy. Looking at the past PCB issues and key findings and also considering development of scientific and technological information and of policy making, Prof Morita evaluated current problems of PCBs in Japan and future perspectives in the elimination road with comparison with other POPs.

Session 1, entitled "PCB environmental fate and transport: Enantioselective analysis," was co-chaired by Keri Hornbuckle and Hans-Joachim Lehmler, both of the University of Iowa.

Although our understanding of the extent and controls on PCB fate and transport is still advancing, it is well known that PCBs are dispersed worldwide. Emissions of PCBs are becoming more prominent in the environment of transition and developing countries, with e-wastes representing a relevant contemporary source factor (Hogarh et al. 2018). Remediation of major sources is inefficient in part because of the limitation in analytical methods for identifying sources and environmental transformation. Advances in measurement methods, including enantioselective analysis of chiral PCBs is accelerating the opportunities for reducing emissions and exposure risks. It is no longer appropriate to measure PCBs using calibration standards based on historical commercial mixtures. The use of Aroclors, Kanechlors, or other nowbanned mixtures in analysis results in serious analytical errors and misguided conclusions (Erickson 2017). Because current production of unintentional PCBs through increasing volume of affected chemical manufacturing processes and products, and because reductive dechlorination can alter the source signal, congener-specific analysis using mass selective techniques is necessary (Zhen et al. 2014). PCB11 is the prime example of a congener that was not produced and sold as a component in commercial mixtures, yet is found in environmental samples worldwide, including schools and homes (Marek et al. 2017). This is but one of several congeners produced unintentionally through the manufacturing of colored pigments (Shang et al. 2014).

Phytoremediation is potentially a cost-effective method for the remediation of sites with widespread contamination (Sharma et al. 2017). However, most plant species cannot absorb and accumulate lipophilic PCBs through their root systems. Some congeners and their metabolites are toxic to plants species (Subramanian et al. 2017). Researchers report successful use of plants as passive biomonitors of PCBs in ambient air as shown by 25 years of PCB biomonitoring by the Bavarian EPA (Weber et al. 2017). This approach has successfully identified point sources and determined regional and global contamination levels and temporal trends of organic pollutants. A study of temporal trends demonstrates that PCB levels in these plants declined significantly in the initial years of $\mathrm{PCB}$ monitoring to levels in the background stations; however, further declines are not evident. Urban levels are several times higher compared to the background sites, with variations consistent with contemporary PCB releases.

Synthetic polymers are often used as passive samplers. These materials provide high-quality data as they can be precleaned and uptake can be predicted as a function of local environmental conditions, properties of the material, and the target chemical. Polyethylene and poly(oxymethylene) sheets were investigated as materials for passive samplers to measure sediment pore water concentrations of PCBs. While poly(oxymethylene) has favorable material properties (i.e., smooth surface and good tensile strength), polyethylene appears to be advantageous in terms of faster attainment of equilibrium. Polyurethane is used to measure PCBs in air and the double-dome design is now commonly used worldwide, with reliable results (Herkert et al. 2016).

Refinement of analytical methods has greatly improved our understanding of PCB sources, fate, and exposure. Detection of picogram quantities using negative ion chemical ionization quadrupole mass spectrometry and triple quadrupole mass spectrometry now enables low-level congener-specific measurements in human blood serum at similar detection limits as high-resolution mass spectrometry and at a lower cost. Similarly, detection and quantification of chiral compounds allows researchers to perform enantioselective analysis of PCBs in complex mixtures (Kania-Korwel and Lehmler 2016). Advanced analytical methods present many opportunities for better understanding of environmental mixtures. For example, recent advances using isotope dilution comprehensive two-dimensional gas chromatography with highresolution time-of-flight mass spectrometry enable simultaneous analysis of PCBs and polychlorinated naphthalenes and congener-specific analysis in complex environmental matrices, including oil and animal tissues. 
Fig. 1 PCBs containing wastes and equipment to be eliminated based on the global inventory survey (UNEP 2016)

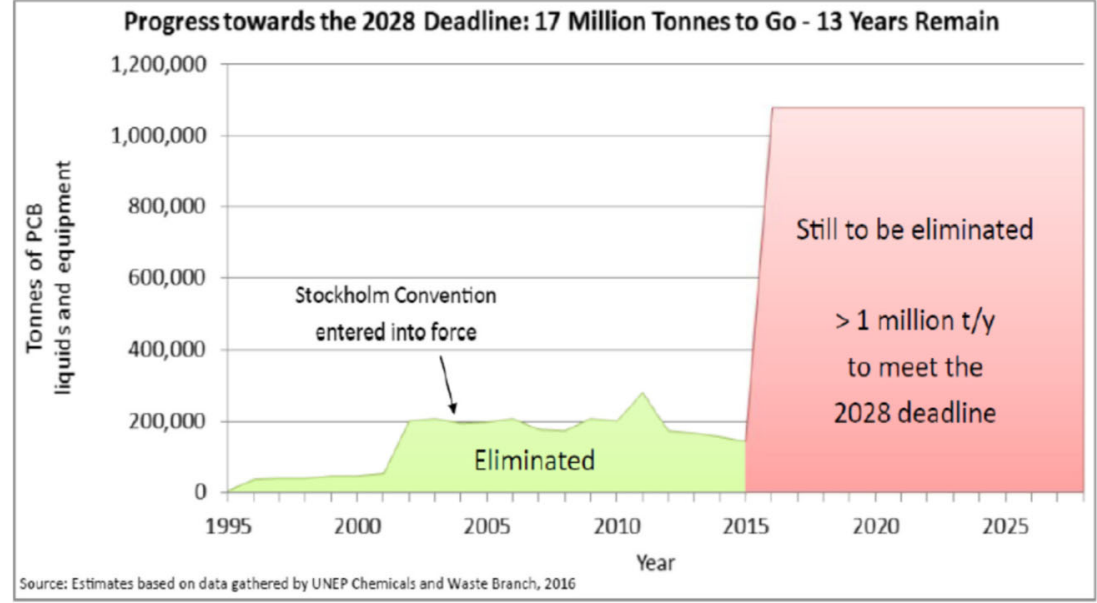

Improvements in analytical and sampling methods enable many important findings about the sources and distribution of PCBs around the world (Diefenbacher et al. 2015). Global contamination is reported in air from Hateruma Island of Okinawa, Japan; coastal estuaries from northeastern region of Vietnam; aquaculture freshwater fish in Ho Chi Minh City, Vietnam; lakes from Japan, Sweden, and the United Sates; sediment and fish from Guánica Bay in the southwest of Puerto Rico; sediment and atmosphere in Hyogo prefecture, Japan; coastal sediments and soils collected from South Korea; soil and sediment from China, with PCB 11 making major contribution to the sum of PCBs; and eggs from caged, free-range, and certified organic farm hens from Poland.

Session 2, entitled "Global inventory and management: National and international activities to limit human and environmental impact of PCBs," was co-chaired by Roland Weber of POPs Environmental Consulting, Schwäbisch Gmünd, and Niklas Johansson of the Karolinska Institute and Melica Biologkonsult. This session focused on international activities in the frame of the Stockholm Convention to eliminate PCBs by 2028 to limit human and environmental impact of PCBs and provided insights into challenges and progress of global management of PCB stocks and waste.

In the first presentation, Jacqueline Alvarez from UNEP Chemicals gave in her presentation on "Efforts toward the elimination of PCBs" an overview on the global PCB inventory and management situation after 12 years of Stockholm Convention implementation. The compiled global inventories of Parties to the Stockholm Convention shows that a total mass of c. 17 million tonnes of PCB-containing liquids and equipment still needs to be eliminated (UNEP 2016) (see Fig. 1). It is estimated that only approximately $17 \%$ of the total amount of PCB has been eliminated to date-with $83 \%$ remaining. Transformers account for the largest share of the total mass. In the African region, c. $98 \%$ of the liquids and equipment containing or contaminated with PCBs still need to be eliminated while c. $86 \%$ remain in the Asia-Pacific Region and Latin American and Caribbean Group (GRULAC), 81\% in the Central and Eastern European Group (CEE), and 36\% in Western European and Others Group (WEOG). It is clear that while some progress has been made toward the elimination of PCBs, the majority of countries and regions are not on track to achieve the goals set out in the Stockholm Convention and that UNEP now recognizes (UNEP/POPS/COP.8/6) that the scope of the challenge of eliminating the use of PCBs by 2025 and achieving the environmentally sound management of PCB by 2028 has been severely underestimated and, as shown in the figure, need large efforts to reach this aim.

Carmela Centeno from UNIDO gave an overview on the global activity of UNIDO toward the elimination of PCBs. One of the core facets of the UNIDO POP program is the provision of services on the environmentally sound management of PCBs. UNIDO strives, when practical, to establish PCB disposal facilities in the country to build internal capacity in addressing POPs issues. Several PCB projects implemented by UNIDO and financed by the Global Enabling Facility (GEF) have leveraged interests of recipient countries on the transfer of non-combustion technologies. UNIDO has assisted in developing the non-combustion PCB waste disposal industries through the provision of technical assistance and leveraging investments of the public and private sectors.

Presentations were given from UNIDO/GEF country projects. Deswandi and Pakpahan from Indonesia showed how UNIDO has assisted in the preparation of PCB inventories when information is incomplete as in Indonesia. Despite considerable efforts in the first inventory phase with more than 3000 analyzed transformers in 1000 industries, less than $1 \%$ of the equipment potentially contaminated by PCBs have been measured in Java and more than 300,000 transformers or other equipment need to be analyzed for the island of Java alone revealing the huge efforts needed in future. Major conclusions for advancing this challenging task are careful industrial mapping, induction meetings, establishment of a dedicated inventory teams and capacity building, and involvement of 
provincial environmental offices. For the Philippines, Leah Aurea Texon (UNIDO) stressed that the National Implementation Plan (NIP) of the Philippines places the environmentally sound management of PCBs as a priority. The Philippines has a non-incineration policy and must rely on non-combustion technology. Through the assistance of UNIDO and funding from the GEF, a PCB destruction facility was established in Bataan Province in the Philippines. Several treatment runs demonstrated that the facility could reduce PCB oils $(<10,000 \mathrm{mg} / \mathrm{kg})$ to the Philippine standards of $<$ $2.0 \mathrm{mg} / \mathrm{kg}$. To sustain the operations of the facility, and at the same time eliminate other POPs containing wastes, a new project focusing on implementing the PCB management plans of electric cooperatives was approved for implementation. Both projects highlights partnership among the government, private sector, civil society, and even lending banks.

Manda (UNITAR) and Pwamang (Ghana EPA) provided an example of PCB management capacity building in Ghana. This effort was supported by the United Nations Institute of Training and Research (UNITAR), United Nations Industrial Development Programme (UNDP), and GEF. Within the project, approx. 10,000 transformers were monitored and the treated PCB-contaminated oil and equipment managed. This included the provision of guidelines and training on proper management and safe disposal of the PCB-containing waste streams and had associated co-benefits for the management and safe destruction of POPs, pesticides, and ozonedepleting substances. As part of the project, Ghana EPA also promulgated, and is mandated for enforcing the control and management of, the Hazardous and Electronic Wastes Act. The Act has a two-tier approach: to regulate the management and disposal of PCBs and to regulate the management of ewaste.

Gao and Peng from the Chinese Ministry of Environmental Protection Foreign Economic Cooperation Office introduced in one presentation the environmental standards, specification, and guidance for the environmental sound management and disposal of PCB waste in China. This holistic approach provides a helpful example of the regulatory frameworks which can be adopted in many countries to ensure that PCBs are dealt with comprehensively, efficiently, and safely. In a second presentation, they gave an overview of the management of the investigation of electrical devices containing PCBs in China. China has disposed of over 30,000 PCB-containing pieces of equipment and completed the disposal of all identified PCBcontaining devices in use and stored over ground. Yet, there are still some underground storage sites that need to be managed. In China, it was found that capacitors account for a much larger proportion of the inventory and that care must be taken not to assume that the majority of PCBs are necessarily found in transformers.

Beskoski and Nakano presented on the PCB management situation and challenges in Serbia. A preliminary inventory has been established within the Stockholm Convention National Implementation Plan. It is estimated that around 2000 tonnes of PCB-contaminated oil or around 8000 tonnes of contaminated equipment can be found in Serbia. The study highlighted that in addition to the PCB stockpiles, PCBcontaminated sites are of high relevance. In Serbia, as a result of the NATO bombing campaign in 1999, an electric transformer station in Bor was heavily damaged and waste containing more than 100 destroyed PCB condensers and around $800 \mathrm{~m}^{2}$ of polluted soil was produced. Also, in the bombed industrial zone of Pancevo, about $25,000 \mathrm{~kg}$ of contaminated sand and equipment are stored in metal barrels. Also, the presentation of Åhr Evertson and colleagues showed that PCBcontaminated sites can turn up unexpectedly even in low industrialized areas like lake Oxundasjön with direct risks to the human food chain by the contamination of inland waters and fish $(500 \mu \mathrm{g} / \mathrm{kg}$ PCB7 fresh weight or total PCB $3000 \mu \mathrm{g} / \mathrm{kg})$. In total, it was estimated that approx. 2 tonnes of PCBs are in the sediments of the lake.

Weber and colleagues documented that PCB-contaminated sites were generated along the entire life cycle of PCBsproduction, use, and end of life-leading to feed and food contamination and contemporary human exposure (Weber et al. 2018). Therefore, these areas should be systematically monitored with respect to food safety and appropriate management measures should be taken for reduction of human exposure. The study highlighted that open PCB applications, like PCB paints in silos and PCB paints on walls, wood parts, or roof of farms applied decades ago, still today result in PCB contamination of lifestock and chickens (Weber et al. 2018).

In the final presentation, Niklas Johansson described how the Swedish Government - probably the most active and progressive authority on open PCB uses - has made systematic efforts to investigate, inventory, and remediate buildings in which PCBs have been used in open applications. This approach could certainly provide a model for many other developped countries where similar open PCB stocks and contamination are likley to be present.

Session 3, entitled "Toxicity and carcinogenicity of PCBs," was co-chaired by Beatrice Lauby-Secretan, International Agency for Research on Cancer, France, and Takesumi Yoshimura, University of Occupational and Environmental Health, Japan, and Emergency Life-Saving Technique Academy of Kyushu, Japan.

A plenary lecture, presented by Prof. Furue, Research and Clinical Center for Yusho and Dioxin, Japan, reported on the latest findings from the Yusho accident. Even today, higher blood levels of PeCDFs have been detected in Yusho patients than in controls. The carcinogenicity of PCBs is evident in the liver and lung in male patients. The adverse effects in high levels of PCB/PCDF were shown to have some adverse effects on pregnancy outcome in Yusho women, and mothers exposed to dioxins before 20 years of age showed an elevated 
ratio in male births. Accelerated elimination of PCBs and dioxins has proven difficult and current attempts have been unsuccessful. One potential therapeutic approach has been to target the aryl hydrocarbon receptor (AhR), using Japanese Kampo formulae.

In the second plenary lecture, entitled "Cancer risk estimation in Yucheng people highly exposed to PCBs and PCDFs based on serum levels 15-24 years after exposure," Prof. Guo, National Institute of Environmental Health Science, Taiwan, presented Yucheng morbidity data compared to neighborhood controls and a recent meta-analysis of Yucheng and Yusho mortality data. It appears that TEQs in Yucheng were higher than those in Yusho. In Taiwan, the Yucheng Health Care Act was executed in 2015 .

The ensuing presentations covered the spread of genetic, biochemical, and cellular effects of PCBs, showing the plethora of pathways by which PCBs exert their toxicity and carcinogenicity: ADME (distribution and accumulation of PCBs in pregnant women); receptor-mediated effects (enantioselective activation of ryanodine receptors (RyR); receptors activated by low molecular weight (MW) PCBs); metabolic activation (identification of new cytochrome P-450 enzymes for bioactivation of $\mathrm{PCBs}$ ); genotoxicity (mutagenicity and telomerase activity); epigenetic effects (DNA hypomethylation), tumor-promoting (non-genotoxic) effects (activity of low-MW-PCBs).

Miroslav Machala, Veterinary Research Institute, Czech Republic, gave a comprehensive review of in vitro toxicity, profiling of low molecular weight PCB congeners. Wei Feng, University of California, USA, discussed the enantioselective actions of PCB 95 atropisomers toward ryanodine receptors (RyRs) and hippocampal neurons. Gabriele Ludewig, University of Iowa, USA, showed how polychlorinated biphenyls (PCBs) target your telomeres, namely which $\mathrm{PCB}$, by which mechanisms, and what the consequences could be (Xin et al. 2016).

Beatrice Lauby-Secretan presented the IARC Monograph on PCBs (IARC 2016) and used PCBs as a model to illustrate the key characteristics of carcinogens as defined by IARC. The next presentation, by Tsuguhide Hori, Fukuoka Institute of Health and Environmental Sciences, Japan, was on distribution and accumulation of dioxins and PCBs in pregnant and nursing women. Finally, Shusaku Hirakawa, Fukuoka Institute of Health and Environmental Sciences, Japan, spoke on the accumulation properties of polychlorinated biphenyl congeners in Yusho patients and assessment of their cytochrome P450-dependent metabolism by in silico docking simulation.

Session 4, "PCB Metabolism and Endocrine Disruption," was co-chaired by Margaret James of the University of Florida and Michael Duffel of the University of Iowa. Margaret James began the session with a presentation entitled "Recent Advances in Understanding PCB Metabolism, Both Lower
Chlorinated and Higher Chlorinated Congeners" that provided an analysis of the recent discoveries on the metabolism of PCBs to more biologically active/toxic molecules. Hideyuki Inui from Kobe University presented "Structural Determinants of Species Differences on Metabolism of Dioxin-like Polychlorinated Biphenyls by Mammalian Cytochrome P450 Monooxygenases," with recent in vitro results on the specificities of human and rat CYP1A and CYP2B isoforms with PCBs such as PCB 77, PCB 118, and PCB 126. Nobuyuki Koga of Nakamura Gakuen University then presented 'Distribution and Excretion of 2,2',3,4',5,5',6Heptachlorobiphenyl (CB187) and its Metabolites in Rats and Guinea Pigs," wherein in vivo results with PCB 187 in these species showed several quantitative differences in metabolism and distribution but demonstrated that both species retained the minor metabolite, 4-OH-PCB 187, in blood. The next presentation, "Toxicological Assessment of PCBs and $\mathrm{OH}-\mathrm{PCB}$ in the Brain of Dogs Using Metabolomics Approach," by Kei Nomiyama of Ehime University, highlighted the use of metabolomics approaches to probe the toxicological effects of OH-PCBs on cellular processes following treatment with well-defined mixtures of PCBs.

Hazuki Mizukawa from Hokkaido University then broadened the range of species differences and endocrine effects considered in the session with a presentation entitled "In Vivo Analysis of PCB Metabolic Capacities and Effects on the Thyroid Hormone in Cats." Satomi MizukamiMurata of the Institute for Agro-Environmental Sciences next described in vitro studies on neuronal toxicity of $\mathrm{OH}-$ PCBs in a presentation entitled "Comparison of the Effects of 20 Kinds-OH-PCBs on PC12 Cells". This was followed by Michael Duffel's presentation of "Sulfation in the Metabolism and Potential Endocrine Toxicities of Airborne PCBs," where the roles of sulfation and sulfotransferases in endocrine disruption by PCB metabolites were emphasized. Finally, Peter Behnisch of BioDetection Systems B.V. outlined rapid in vitro methods for toxicological risk assessment in his presentation entitled "The 'Dirty Dozen' POPS \& Other Pollutants: Toxicological Profiling by In Vitro Bioassays." The session emphasized the importance of considering metabolism in studying the toxicities of PCBs.

Wednesday's program began with a Plenary Lecturer, Shinichi Sakai, Professor at Kyoto University. His lecture, entitled "PCB Behavior and Control from the Points of Waste Destruction and Byproducts Formation" introduced the law concerning the examination and regulation of manufacture of chemical substances established in 1973, which reviews and regulates the use of chemical substances. In addition, the law concerning special measures against $\mathrm{PCB}$ waste was enacted in 2001 to promote secure and appropriate treatment of PCB wastes. These laws were enacted as a result of the 1968 Yusho incident. He also talked about 
environmental problems related to release of unintentionally and intentionally produced dioxin-like PCBs.

Session 5, entitled "Human Exposures," was chaired by Nobuyuki Koga of Nakamura Gakuen University and Tomas Trnovec of Slovak Medical University.

From various approaches for monitoring of human exposures to polychlorinated biphenyls, this session was targeting the noninvasive monitoring of human milk. Rainer Malisch reported on present state of the WHO global survey on concentration of PCDDs, PCDFs, and PCB in human milk of donors from 69 countries. The downward trend in most of the countries has been confirmed. Next speaker Risa Kakimoto treated the problem of reproducibility of determination of PCBs in human milk and concluded with some valuable recommendations on study design. The presentation of Shin Takahashi reported on concerns connected with recycling of electronic wastes and of disposal of end of life vehicles. These practices exposing populations mainly of developing countries to PCBs and BFRs should be studied and regulatory measures be implemented. A very useful tool for human biomonitoring is the cell- and effect-based bioanalysis. Peter Behnisch and colleagues reported on the state of the art in the area of biomonitoring of chlorinated and brominated PCB-/dioxin-contaminated areas and analyzed the associated risk to human health. An excellent case study of environmental exposure to PCBs was outlined by Andres Martinez of the University of Iowa. He reported on the release of PCBs from New Bedford Harbor and concluded that it is one of the largest ongoing sources of airborne PCBs. In course of the last decade, many reports have appeared on indoor exposure to PCBs. The report presented by Majbrith Langeland from Denmark summarized the extensive activities of the authorities to decrease the risk arising from using of PCBs in construction materials. The most hazardous materials were identified and ways to their elimination were indicated. The final presentation of this session by Bernhard Hennig was on ways how to combat the health outcomes of exposure to persistent organic pollutants.

Session 6 entitled "Risk Evaluation and environmental Protection" was co-chaired by Yasuhiro Hirai of Kyoto University and David Osterberg of the University of Iowa.

Session 6 presentations were on PCB risk evaluation and environmental protection emphasizing how contaminated sites may contribute to airborne exposures and community concern about PCBs. Of special note was the discussion of community involvement in a study of New Bedford Harbor. Located in southern Massachusetts, the 18,000-acre New Bedford Harbor Superfund site (NBH) is one of the nation's largest sites contaminated with PCBs. Immediately adjacent to the harbor lies several communities, including the city of New Bedford. The cleanup plan for NBH includes dredging of the contaminated sediment and disposal in an on-site confined aquatic disposal (CAD) cell in the lower harbor. Although the United States Environmental Protection Agency reported that inhalation did not present significant risk to human health, the people living nearby were concerned about airborne PCBs. Residents of New Bedford and nearby Fairhaven requested technical expertise and scientific assistance from the Boston University and University of Iowa Superfund Research Programs. A project called "Emissions and dispersion of airborne PCB congeners from New Bedford Harbor into nearby residential communities" was completed. The project included collection of PCBs using passive air samplers with polyurethane foam (PUF-PAS). The samplers were hosted by residents and provided airborne $\mathrm{PCB}$ concentrations that were then compared with emissions predicted from environmental modeling. The research was conducted in collaboration with three primary communities: (i) municipal boards of health and health departments in Massachusetts, (ii) residents living in proximity to federal- and state-designated hazardous waste sites, and iii) residents of environmental justice areas. The work addressed current gaps in the understanding of the ambient air concentrations of the community, although additional questions arose as participants' understanding of the science grew. The project provided the following: (i) estimates of PCB emissions from the contaminated water of New Bedford Harbor (NBH); (ii) a prediction of the airborne $\mathrm{PCB}$ concentrations in the surrounding community due to emissions from the harbor; (iii) airborne PCB measurements to assess the accuracy and usefulness of the predictions; and (iv) evaluation of the contribution of $\mathrm{PCBs}$ from the $\mathrm{NBH}$ waters to the surrounding community in response to concerns raised by the local community regarding the PCBs in the air during dredging of the sediments in the harbor. The project concluded that the community concerns were reasonable: emissions of PCBs from the harbor did explain the concentrations found in air. Furthermore, the research showed that emissions had been ongoing for many decades and were not initiated by dredging activities (Tomsho et al. 2017).

\section{References}

Diefenbacher PS, Bogdal C, Gerecke AC, Gluge J, Schmid P, Scheringer M, Hungerbuhler K (2015) Emissions of polychlorinated biphenyls in Switzerland: a combination of long-term measurements and modeling. Environ Sci Technol 49:2199-2206. https://doi.org/10. $1021 / \mathrm{es} 505242 \mathrm{~d}$

Erickson MD (2017) Aroclor misidentification in environmental samples: how do we communicate more effectively between the laboratory and the data user? Environ Sci Pollut Res. https://doi.org/10.1007/ s11356-017-0160-6 
Herkert NJ, Martinez A, Hornbuckle KC (2016) A model using local weather data to determine the effective sampling volume for PCB congeners collected on passive air samplers. Environ Sci Technol 50:6690-6697. https://doi.org/10.1021/acs.est.6b00319

Hogarh JN, Seike N, Kobara Y, Carboo D, Fobil JN, Masunaga S (2018) Source characterization and risk of exposure to atmospheric polychlorinated biphenyls (PCBs) in Ghana. Environ Sci Pollut Res. https://doi.org/10.1007/s11356-018-2090-3

IARC 2016: Polychlorinated biphenyls and polybrominated biphenyls, International Agency for Research on Cancer, World Health Organization. http://monographs.iarc.fr/ENG/Monographs/vol107/ mono107-001.pdf

Kania-Korwel I, Lehmler HJ (2016) Chiral polychlorinated biphenyls: absorption, metabolism and excretion-a review. Environ Sci Pollut Res 23:2042-2057. https://doi.org/10.1007/s11356-015-4150-2

Marek RF, Thome PS, Herkert NJ, Awad AM, Hornbuckle KC (2017) Airborne PCBs and OH-PCBs inside and outside urban and rural US schools. Environ Sci Technol 51:7853-7860. https://doi.org/10. 1021/acs.est.7b01910

Shang HT, Li YM, Wang T, Wang P, Zhang HD, Zhang QH, Jiang GB (2014) The presence of polychlorinated biphenyls in yellow pigment products in China with emphasis on 3,3'-dichlorobiphenyl (PCB 11). Chemosphere 98:44-50. https://doi.org/10.1016/j. chemosphere.2013.09.075

Sharma JK, Gautam RK, Nanekar SV, Weber R, Singh BK, Singh SK, Juwarkar AA (2017) Advances and perspective in bioremediation of polychlorinated biphenyl-contaminated soils. Environ Sci Pollut Res Int. https://doi.org/10.1007/s11356-017-8995-4

Subramanian S, Schnoor JL, Van Aken B (2017) Effects of polychlorinated biphenyls (PCBs) and their hydroxylated metabolites (OH-PCBs) on Arabidopsis thaliana. Environ Sci Technol 51: 7263-7270. https://doi.org/10.1021/acs.est.7b01538

Tomsho KS, Basra K, Rubin SM, Miller CB, Juang R, Broude S, Martinez A, Hornbuckle KC, Heiger-Bernays W, Scammell MK (2017) Community reporting of ambient air polychlorinated biphenyl concentrations near a superfund site. Environ Sci Pollut Res Int. https://doi.org/10.1007/s11356-017-0286-6

UNEP (2016) Consolidated assessment of efforts made toward the elimination of polychlorinated biphenyls prepared by UNEP on the basis of the third national reports submitted by parties pursuant to article 15 of the Stockholm Convention., UNEP/DTIE, Chemicals and Waste Branch.

Weber R, Gonser S, Köhler J, Körner W, Herold C, Haag R, Krapp M, Peichl L (2017) Biomonitoring of polychlorinated biphenyls in Bavaria/Germany long-term observations and standardization. Environ Sci Pollut Res Int. https://doi.org/10.1007/s11356-0171108-6

Weber R, Herold C, Hollert H, Kamphues J, Ungemach L, Blepp M, Ballschmiter K (2018) Life cycle of PCBs and contamination of the environment and of food products from animal origin. Environ Sci Pollut Res Int. https://doi.org/10.1007/s11356-018-1811-y

Xin X, Senthilkumar PK, Schnoor JL, Ludewig G (2016) Effects of PCB126 and PCB153 on telomerase activity and telomere length in undifferentiated and differentiated HL-60 cells. Environ Sci Pollut Res Int 23:2173-2185. https://doi.org/10.1007/s11356-0155187-y.

Zhen HJ, Du SY, Rodenburg LA, Mainelis G, Fennell DE (2014) Reductive dechlorination of 1,2,3,7,8-pentachlorodibenzo-p-dioxin and Aroclor 1260, 1254 and 1242 by a mixed culture containing Dehalococcoides mecartyi strain 195 . Water Res 52:51-62. https:// doi.org/10.1016/j.watres.2013.12.038

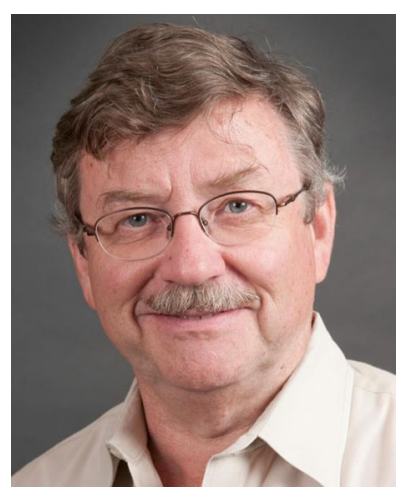

Larry W. Robertson $\mathrm{PhD}$, MPH, ATS, is Professor of Toxicology in the Department of Occupational and Environmental Health at the University of Iowa. He is the Program Director of the Iowa Superfund Program, entitled "Semi-volatile PCBs: Sources, Exposures, Toxicities" which has been funded from May 2006 to the present. Dr. Robertson is also the Director of the Interdisciplinary Graduate Program in Human Toxicology. Before moving to the University of Iowa, Dr. Robertson was the Founding Director of the University of Kentucky Superfund Basic Research Program from its initial funding on April 1, 1997, until March 31, 2003, when he left the UK to join the faculty of the University of Iowa. Dr. Robertson earned a BA in Chemistry from Stetson University, an MS in Microbiology from the University of Florida, and an M.P.H. and Ph.D. in Environmental Health Sciences from the University of Michigan. He was a Research Associate with Prof. Steve Safe at Texas A\&M University before receiving an Alexander von Humboldt Research Fellowship and traveling to Germany to study with Prof. Franz Oesch at the University of Mainz. There he took a post-fellowship position as a Project Leader in SFB 302 "Early Stages in Carcinogenesis." Dr. Robertson joined the University of Kentucky's Graduate Center for Toxicology in 1986, was promoted to tenure July 1, 1989, and was promoted to Full Professor July 1, 1996. Dr. Robertson's primary area of research is the mechanism(s) of toxicity of polyhalogenated aromatic hydrocarbons, including the polychlorinated biphenyls (PCBs), dibenzodioxins, dibenzofurans, and various pesticides. Dr. Robertson's research on these environmental pollutants include studies of their effects on gene regulation, their metabolism to electrophilic species, and their binding to nucleophiles, including amino acids, nucleotides and DNA, and the involvement of these processes in the initiation and promotion of carcinogenesis. Dr. Robertson has published more than 290 articles on these topics. Dr. Robertson organized, and obtained funding for, nine International PCB Workshops, the last of which took place in Kobe, Japan, October 9-13, 2016 (http://ee-net.ne.jp/pcb2016e).

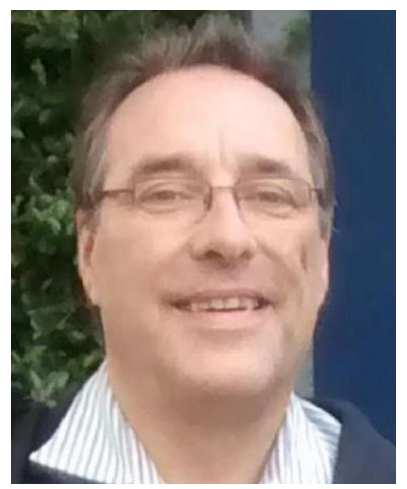

Dr. Roland Weber has been working since 2003 as an independent international consultant mainly for UN Organizations (UNEP, UNIDO, UNDP) and environmental ministries on the implementation of the Stockholm Convention on Persistent Organic Pollutants (POPs). His areas of particular expertise include dioxins, other unintentionally produced POPs, and brominated and fluorinated POPs and POPs-like chemicals. He is drafter/co-drafter of several technical guidance documents for the Stockholm Convention and a member of the UNEA/Stockholm Convention BAT/BEP expert group. He coauthored the Mediterranean action plan for sustainable consumption and production (SCP) and the SCP toolkit for policy makers. He is an 
active member of the "global POPs research community," is a member of the Editorial Board of ESPR, and has published more than 120 peerreviewed papers (www.researchgate.net/profile/Roland_Weber3). He received his $\mathrm{PhD}$ in 1996 from Tübingen University and worked from 1997 to 2002 as head of a Dioxin/POPs R\&D laboratory for IHI Co Ltd. (Yokohama/Japan) with research cooperation to Kyoto and Ritzumeikan Universities. Since 2010, Dr. Weber is a visiting Professor at the Tsinghua University POPs Research Centre in Beijing.

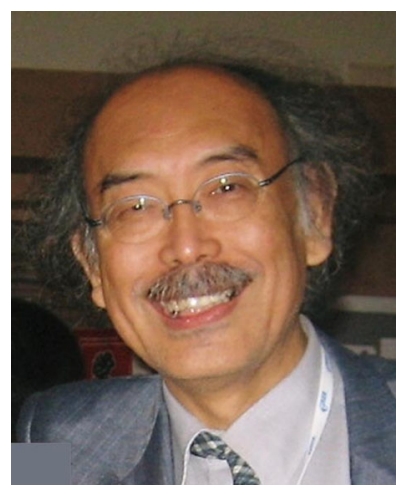

Takeshi Nakano was born in 1949 in Kobe and obtained a master degree in Applied Chemistry from Osaka University, Japan, in 1974, and a Ph.D. at the same university (Studies on CongenerSpecific Analysis of Chlorinated Aromatics and its Application to Environmental Chemistry) in 2007. In 1974, he joined the Hyogo Prefectural Institute of Environmental Science for more than 40 years. He contributed to the field of congener-specific analysis for dioxin and related compounds. His main expertise is in the field of persistent organic pollutants (POPs), especially dioxins as well as PCBs in human and environmental samples as well as enantioselective analysis for chiral compounds such as PCB, HCH, DDT, and chlordanes. He is contributing to various POP-related committees under the Ministry of Environment of Japan such as POP monitoring, PCB destruction project, unintentional formation of POPs. He co-organized the International Conference of Asian Environmental Chemistry in 2014 and the 9th PCB Workshop in 2016 in Kobe Japan. Since 2014, he is contributing to the JICA (executing agency for technical cooperation of the Government of Japan) grass root project "Capacity Building for Analysis and Reduction Measures of Persistent Organic Pollutants in Serbia" as project leader (globalgreengroup.org/people.html). He maintains voluntary webserver (ee-net.ne.jp) for sharing information of environmental, analytical, and technical issue as chief member of the MS analysis commission of the Japanese water environment society. His hobby is to record researcher's natural smile as official photographer of the Dioxin Conference series (ee-net.ne.jp/dioxin/) and other Conferences (http://eenet.ne.jp/pcb2016e).

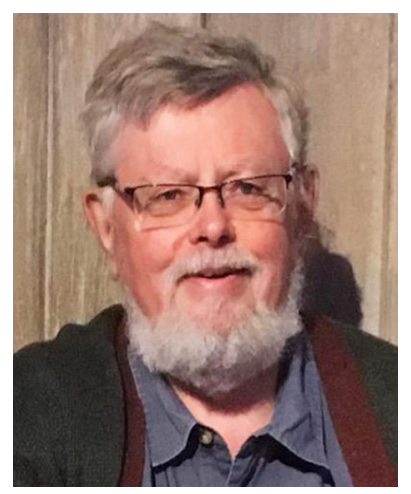

Niklas Johansson was born in Uppsala in 1946. In 1967, he began his studies at Uppsala University. During 1971 until 1978 , he was a PhD student in Ecotoxicology at the Department of Zoophysiology. Then he went to Swedish EPA where he stayed until 2013. In parallel, he was also a scientist at Karolinska Institute where he still has a position. Since 2013, Niklas continues to be active as an environmental consultant, mainly dealing with PCBs and other POPs. 